\title{
Development and evaluation of a building energy model integrated in the TEB scheme
}

\author{
B. Bueno ${ }^{1,2}$, G. Pigeon ${ }^{1}$, L. K. Norford ${ }^{2}$, K. Zibouche ${ }^{3}$, and C. Marchadier ${ }^{1}$ \\ ${ }^{1}$ CNRM-GAME, URA1357, CNRS - Météo France, Toulouse, France \\ ${ }^{2}$ Massachusetts Institute of Technology, Cambridge, USA \\ ${ }^{3}$ Université Paris-Est, Centre Scientifique et Technique du Bâtiment (CSTB), France \\ Correspondence to: B. Bueno (bbueno@mit.edu)
}

Received: 13 September 2011 - Published in Geosci. Model Dev. Discuss.: 15 November 2011

Revised: 5 March 2012 - Accepted: 19 March 2012 - Published: 29 March 2012

\begin{abstract}
The use of air-conditioning systems is expected to increase as a consequence of global-scale and urban-scale climate warming. In order to represent future scenarios of urban climate and building energy consumption, the Town Energy Balance (TEB) scheme must be improved. This paper presents a new building energy model (BEM) that has been integrated in the TEB scheme. BEM-TEB makes it possible to represent the energy effects of buildings and building systems on the urban climate and to estimate the building energy consumption at city scale $(\sim 10 \mathrm{~km})$ with a resolution of a neighbourhood $(\sim 100 \mathrm{~m})$. The physical and geometric definition of buildings in BEM has been intentionally kept as simple as possible, while maintaining the required features of a comprehensive building energy model. The model considers a single thermal zone, where the thermal inertia of building materials associated with multiple levels is represented by a generic thermal mass. The model accounts for heat gains due to transmitted solar radiation, heat conduction through the enclosure, infiltration, ventilation, and internal heat gains. BEM allows for previously unavailable sophistication in the modelling of air-conditioning systems. It accounts for the dependence of the system capacity and efficiency on indoor and outdoor air temperatures and solves the dehumidification of the air passing through the system. Furthermore, BEM includes specific models for passive systems, such as window shadowing devices and natural ventilation. BEM has satisfactorily passed different evaluation processes, including testing its modelling assumptions, verifying that the chosen equations are solved correctly, and validating the model with field data.
\end{abstract}

\section{Introduction}

The energy consumption of heating, ventilation and airconditioning (HVAC) systems in buildings has become an important factor in the design and analysis of urban areas. HVAC systems are responsible for waste heat emissions that can contribute (among other causes) to the increase in air temperature observed in urban areas with respect to their undeveloped rural surroundings (Bueno et al., 2012; de Munck et al., 2012). This increase in air temperature in cities, a phenomenon known as the urban heat island (UHI) effect, can affect the energy consumption of HVAC systems and the waste heat emissions associated with them. The use of HVAC systems is expected to increase in the following years as a consequence of global-scale and urban-scale climate warming (Adnot, 2003); therefore, urban climate models, such as the Town Energy Balance (TEB) scheme (Masson, 2000), must be improved in order to represent future scenarios of climate conditions and energy consumption in urban areas.

The TEB model is a physically based urban canopy model that represents the fluid dynamic and thermodynamic effects of an urbanized area on the atmosphere. This model has been evaluated with observations in various urban sites and weather conditions (Masson et al., 2002; Lemonsu et al., 2004; Offerle et al., 2005; Pigeon et al., 2008; Hamdi and Masson, 2008; Lemonsu et al., 2010). Previous versions of the TEB model implement a simple representation of building energy processes by solving a transient heat conduction equation through a multi-layered wall and roof. The force-restore method is applied to calculate indoor conditions from the contributions of the different building surfaces. A 
minimum indoor air temperature threshold is used to calculate the heating loads of the building associated with transmission through building surfaces (Pigeon et al., 2008).

In order to improve the representation of buildings in TEB, we have considered two different approaches. The first approach is to couple a well-known building energy model, such as EnergyPlus (Crawley et al., 2001), with TEB. This is the strategy adopted in Bueno et al. (2011). However, the coupled scheme (CS) developed in this study requires a number of iterations between the two models, which makes it unsuitable for coupling with atmospheric models.

The second approach is to develop a new building energy model (BEM) integrated in the urban canopy model. This is the method used by Kikegawa et al. (2003) and Salamanca et al. (2010). They developed simplified building energy models that are able to capture the main heat transfer processes that occur inside buildings and to calculate building energy demand, HVAC energy consumption and waste heat emissions (Kondo and Kikegawa, 2003; Salamanca and Martilli, 2010; Kikegawa et al., 2006; Ihara et al., 2008). However, they consider idealized HVAC systems and do not take into account passive building systems. Following the same method, this paper presents a BEM integrated in the TEB model that overcomes the limitations of the previous models.

In this study, BEM-TEB is evaluated at three levels: modelling assumptions; model verification, based on a comparison with the CS; and model validation, based on a comparison with field data from two experiments, Toulouse (Masson et al., 2008) and Athens (Synnefa et al., 2010).

\section{Model description}

\subsection{Objective and main features}

BEM-TEM constitutes a new version of the urban canopy model TEB, in which the energy effects of buildings in the urban climate are better represented. The new version of the model makes it possible to calculate building energy consumption at city or neighbourhood scale. Previous versions of TEB could not calculate cooling energy consumption of buildings and the waste heat emissions associated with HVAC systems.

BEM calculates the energy demand of a building by applying a heat balance method. It considers a single thermal zone and represents the thermal inertia of various building levels by a generic thermal mass. The model accounts for solar radiation through windows, heat conduction through the enclosure, internal heat gains, infiltration and ventilation (Fig. 1).

BEM includes specific models for active and passive building systems. It considers the dependence of the cooling system efficiency on indoor and outdoor temperatures and solves the dehumidification of the air passing through the system. Passive building systems such as window shadowing devices and natural ventilation are represented in BEM.
The model has been kept as simple as possible, while maintaining the required features of a comprehensive building energy model. We have intentionally avoided detailed building calculations that would have affected the computational efficiency of the TEB model without providing a significant gain in accuracy.

\subsection{Geometry and building definition}

BEM uses the same geometric principles as the TEB model, which can be summarized as:

- Homogenous urban morphology. Building enclosure is defined by an average-oriented façade and a flat roof.

- Uniform glazing ratio. BEM assumes that all building façades have the same fraction of glazed surface with respect to their total surface.

In addition, the following is assumed to define buildings in BEM:

- Single thermal zone. BEM assumes that all buildings in a particular urban area have the same indoor air temperature and humidity. This approach is justified if the objective is to calculate the overall energy consumption of a building (or neighbourhood), rather than the energy performance of a specific building zone.

- Internal thermal mass. In the single-zone approach, an internal thermal mass represents the thermal inertia of the construction materials inside a building (e.g. separation between building levels). The transmitted solar radiation and the radiant fraction of internal heat gains are perfectly absorbed by the internal thermal mass and then released into the indoor environment.

- Adiabatic ground floor. The current version of BEM assumes that the surface of the building in contact with the ground is well-insulated.

\subsection{Heat balance method}

BEM uses a heat balance method to calculate indoor thermal conditions and building energy demand. An energy balance is applied to each indoor surface (si: wall, window, floor, roof, and internal mass), accounting for conduction, convection, and radiation heat components, viz.

$Q_{\mathrm{cd}}+Q_{\mathrm{cv}}+\sum_{\mathrm{si}} Q_{\mathrm{rd}}=0$.

The convection and radiation terms are calculated from a standard heat transfer coefficient formulation, $Q=h \Delta T$ (see Appendix A). Convective heat transfer coefficients depend on the relative position between the surface and the indoor air. Radiative heat transfer coefficients are obtained from linearization of the Stefan-Boltzmann equation, assuming only 


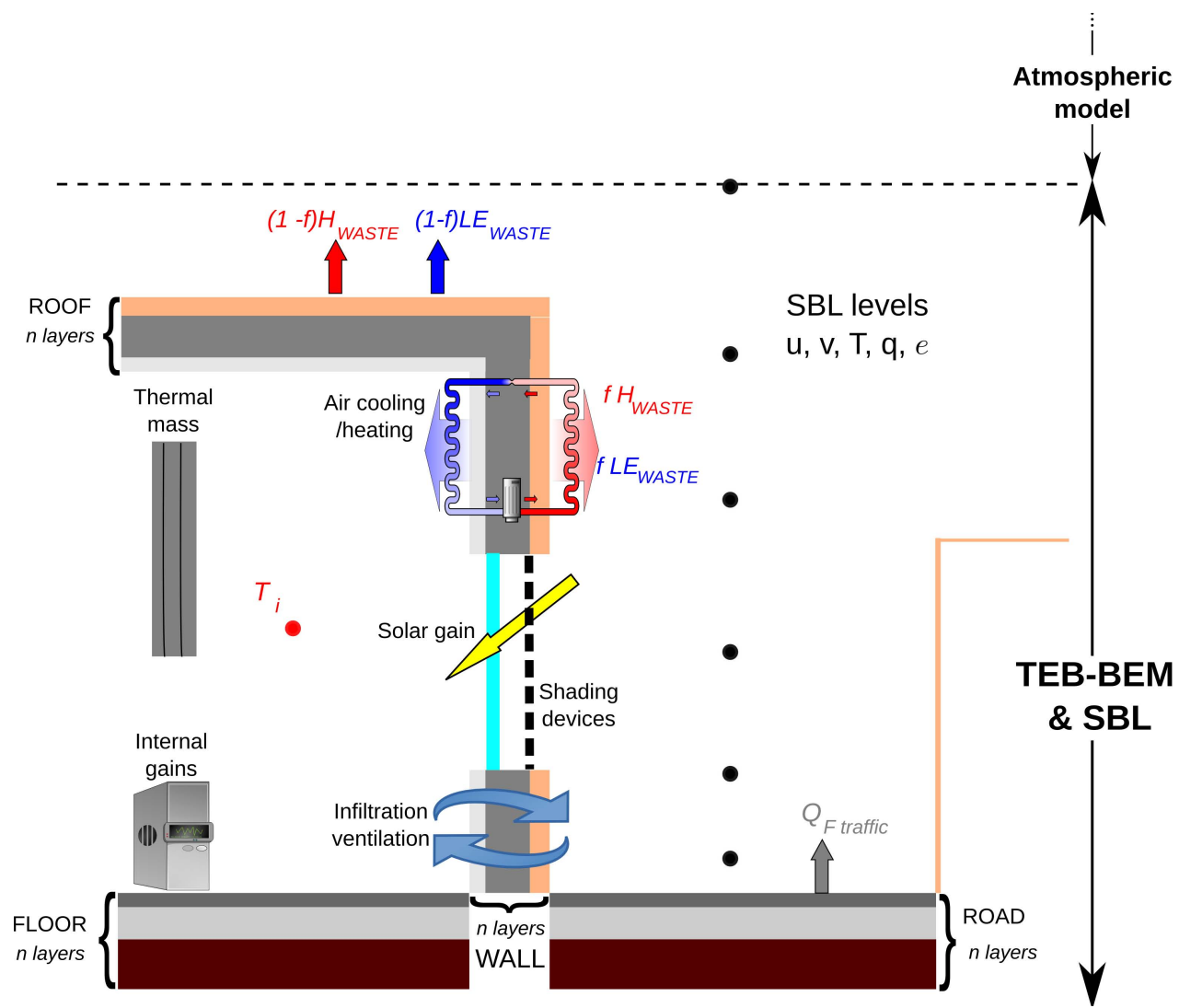

Fig. 1. Diagram of a building and an urban canyon. The main physical processes included in BEM-TEB are represented: heat storage in building and urban construction materials, internal heat gains, solar heat fluxes, waste heat from HVAC systems, etc. The diagram also represents the multi-layer version of the TEB scheme (Hamdi and Masson, 2008) and the possibility of coupling it with an atmospheric mesoscale model.

one bounce of radiative heat fluxes between surfaces. The transient heat conduction through massive building elements (walls, floor, roof, and internal mass) is calculated using TEB routines, which are based on the finite difference method.

To calculate the dynamic evolution of indoor air temperature between a cooling and a heating thermal set point, BEM solves a sensible heat balance at the indoor air. The sensible heat balance is composed of the convective heat fluxes from indoor surfaces, the convective fraction of internal heat gains, the infiltration sensible heat flux, and the sensible heat flux supplied by the HVAC system.

$$
\begin{aligned}
& V_{\text {bld }} \rho c_{\mathrm{p}} \frac{d T_{\text {in }}}{d t}=\sum_{\text {si }} A_{\text {si }} h_{\mathrm{cv}, \mathrm{si}}\left(T_{\mathrm{si}}-T_{\text {in }}\right) \\
& +Q_{\text {ig }}\left(1-f_{\text {rd }}\right)\left(1-f_{\text {lat }}\right) \\
& +\dot{V}_{\text {inf }} \rho c_{\mathrm{p}}\left(T_{\text {urb }}-T_{\text {in }}\right) \\
& +\dot{m}_{\text {sys }} c_{\mathrm{p}}\left(T_{\text {sys }}-T_{\text {in }}\right),
\end{aligned}
$$

where $T_{i n}$ is the indoor air temperature; $V_{\mathrm{bld}}, \rho$, and $c_{\mathrm{p}}$ are the volume, density and specific heat of the indoor air, respectively; $A_{\text {si }}$ is the area of the indoor surface; $Q_{\text {ig }}$ represents the internal heat gains; $f_{\text {lat }}$ is the latent fraction of internal heat gains; $f_{\text {rd }}$ is the radiant fraction of sensible internal heat gains; $\dot{V}_{\text {inf }}$ is the infiltration air flowrate; $T_{\text {urb }}$ is the outdoor air temperature; and $\dot{m}_{\text {sys }}$ and $T_{\text {sys }}$ are the mass flowrate and temperature of the air supplied by the HVAC system.

A latent heat balance is also solved to calculate the dynamic evolution of indoor air humidity. The latent heat balance is composed of the latent fraction of internal heat gains, the infiltration latent heat flux, and the latent heat flux supplied by the HVAC system.

$$
V_{\text {bld }} \rho l_{\mathrm{v}} \frac{d q_{\text {in }}}{d t}=Q_{\text {ig }} f_{\text {lat }}+\dot{V}_{\text {inf }} \rho l_{\mathrm{v}}\left(q_{\text {urb }}-q_{\text {in }}\right)+\dot{m}_{\text {sys }} l_{\mathrm{v}}\left(q_{\text {sys }}-q_{\text {in }}\right),
$$

where $l_{\mathrm{v}}$ is the water condensation heat, and $q_{\mathrm{in}}, q_{\mathrm{urb}}$ and $q_{\mathrm{sys}}$ are the specific humidity of the indoor air, of the outdoor air, and of the air supplied by the HVAC system, respectively.

The building energy demand is calculated by applying the same sensible and latent heat balances at the indoor air, but assuming that this is at set point conditions. The specific humidity set point used for latent energy demand calculations is obtained from the relative humidity set point and the cooling or the heating temperature set point, which are provided by the user.

$Q_{\mathrm{dem}, \mathrm{sens}}=\sum_{\mathrm{si}} Q_{\mathrm{cv}, \mathrm{si}}+Q_{\mathrm{ig}, \mathrm{sens}}+Q_{\mathrm{inf} / \mathrm{vent}, \mathrm{sens},}$ 


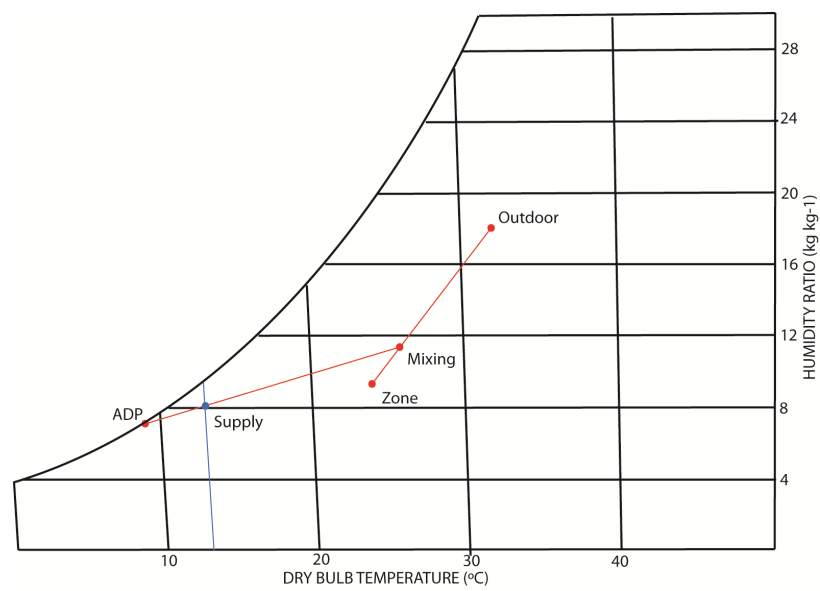

Fig. 2. Psychrometric chart of humid air. The significant points of the HVAC system model for a cooling situation are represented. Zone conditions refer to the temperature and humidity of the indoor air. Recirculated air from the zone is mixed with outdoor air before entering the cooling coil (mixing conditions). The air leaves the cooling coil at supply conditions. The apparatus dewpoint (ADP) is an input of the model and represents the temperature of the air leaving the cooling coil if this would be saturated.

$Q_{\text {dem,lat }}=Q_{\text {ig }, \text { lat }}+Q_{\text {inf } / \text { vent,lat }}$.

\subsection{Windows and solar heat transmission}

Window effects have been introduced in the outdoor energy balance of the TEB model. The external surfaces of windows participate in the outdoor energy balance in the same manner as other urban surfaces (walls, road, garden, etc.). Window surfaces are semi-transparent and therefore have three optical properties (albedo, absorptivity, and transmittance). Two coupled surface energy balances are solved to calculate the internal and external surface temperatures of windows. Each surface energy balance accounts for the convective and radiative heat fluxes reaching the surface and the steady-state heat conduction through the window.

Building energy models usually consider the dependence of the solar heat transmitted through windows on the angle of incidence of the sun. However, simulations with EnergyPlus for different window orientations show that for an averageoriented canyon, the solar transmittance of windows $\left(\tau_{\text {win }}\right)$ can be approximated by a uniform value of 0.75 times the solar heat gain coefficient (SHGC) (see Appendix A). The SHGC can be found in window catalogues and represents the fraction of incoming solar radiation that participates in the indoor energy balance. The solar heat transmitted through windows $\left(Q_{\text {sol,win }}\right)$ is then calculated as:

$Q_{\mathrm{sol}, \mathrm{win}}=Q_{\mathrm{sol}, \mathrm{w}} \tau_{\mathrm{win}} \mathrm{GR}$,

where $Q_{\text {sol,w }}$ is the solar radiation reaching the building façade and GR is the glazing ratio.
The solar absorptivity of windows is calculated as a function of the U-factor and the SHGC, by using the equations proposed in EnergyPlus documentation (DOE, 2010). The U-factor can also be found in window catalogues and measures the window conductance, including the convective and longwave heat transfer coefficients at both sides of the window.

The window albedo is calculated so that the three optical properties (albedo, absorptivity, and transmittance) sum to unity. Then, the model uses an area-averaged façade albedo to calculate solar reflections by weighting the albedo of walls and windows with the glazing ratio of buildings.

\subsection{Passive building systems}

Passive building systems take advantage of the sun, the wind and environmental conditions to reduce or eliminate the need for HVAC systems. Accurate simulation of their effect is sometimes crucial in predicting the overall energy performance of buildings (e.g. Bueno et al., 2011). Moreover, they are among the strategies promoted by governments throughout the world to reduce the energy consumption and greenhouse gas emissions of buildings.

\subsubsection{Natural ventilation}

In residential buildings in summer (especially when an active cooling system is not available), occupants usually open their windows to naturally ventilate indoor spaces. To represent this situation, BEM includes a natural ventilation module, which modifies the indoor air energy balance (Eqs. 2 and 3) by including an outdoor air flowrate term, similarly to the infiltration term. If the conditions are favourable for natural ventilation, the HVAC system is assumed to be turned off at least during one hour. The natural ventilation air flowrate is calculated from a correlation that depends on the outdoor air velocity, the indoor and outdoor air temperatures, and the geometry of buildings and windows (see Appendix A).

\subsubsection{Window shades}

BEM also includes a simplified model to account for window shadowing devices. If the solar radiation reaching the window is above a predefined threshold, the model considers that shades are placed outside and in front of the windows. These shades are characterized by a predefined transmittance. The model reduces the solar radiation reaching the windows by changing its optical properties. The solar radiation that is not reflected, absorbed, or transmitted by the windows is assumed to be converted into a sensible heat flux towards the urban canyon. 


\subsection{HVAC system}

\subsubsection{Ideal and realistic definitions of an HVAC system}

BEM includes both an ideal and a realistic definition of an HVAC system. In the ideal definition, the system capacity is infinite, and the system supplies the exact amount of energy required to maintain indoor thermal and humidity set points. On the contrary, the realistic definition considers a finite capacity that can be provided by the user or calculated by the autosize function (see Sect. 2.6.7).

In the case of a cooling system, the realistic definition also takes into account the dependence of the system capacity and efficiency on outdoor and indoor conditions. Furthermore, the system efficiency is affected by part-load performance, when the system does not work at its nominal capacity. The realistic definition of the cooling system solves for the dehumidification of the air passing through the cooling coil. In most HVAC system configurations, the indoor air humidity is not controlled in the same way as the air temperature, so the calculation of the air humidity requires a psychrometric model of the air crossing the system. Figure 2 represents a psychrometric chart of humid air and the significant points of the HVAC model for a cooling situation (summer).

\subsubsection{Mixing conditions}

To calculate the supply air conditions and the energy consumption of the HVAC system, the model first calculates the mixing conditions of the air recirculated from the building and the outdoor air required for ventilation. This calculation is the same for both the cooling and the heating system models. The mixing ratio $\left(X_{\mathrm{mix}}\right)$ is calculated as $X_{\text {mix }}=$ $\dot{V}_{\text {vent }} \rho / \dot{m}_{\text {sys }}$, where $\dot{m}_{\text {sys }}$ is the supply air mass flowrate and $\dot{V}_{\text {vent }}$ is the ventilation air volume flowrate, which are given by the user (or calculated by the autosize function in the case of the air mass flowrate). Then, the mixing air temperature and humidity are calculated from the building air temperature and the outdoor air temperature as follows:

$T_{\text {mix }}=X_{\text {mix }} T_{\text {urb }}+\left(1-X_{\text {mix }}\right) T_{\text {in }}$,

and

$q_{\text {mix }}=X_{\text {mix }} q_{\text {urb }}+\left(1-X_{\text {mix }}\right) q_{\text {in }}$.

\subsubsection{Cooling system}

In the ideal cooling system model, the energy consumption is calculated by adding the sensible and the latent energy demand of the building and dividing by the system coefficient of performance $(\mathrm{COP}), Q_{\mathrm{HVAC} \text {, cool }}=Q_{\mathrm{dem} \text {, cool }} / \mathrm{COP}$. The supply conditions are then calculated to meet the building energy demand:

$T_{\text {sys }}=T_{\text {mix }}-H_{\text {dem, cool }} /\left(\dot{m}_{\text {sys }} c_{\mathrm{p}}\right)$,

and

$q_{\mathrm{sys}}=q_{\mathrm{mix}}-\mathrm{LE}_{\mathrm{dem}, \mathrm{cool}} /\left(\dot{m}_{\mathrm{sys}} l_{\mathrm{v}}\right)$, where $H_{\mathrm{dem}, \text { cool }}$ and $L E_{\mathrm{dem}, \mathrm{cool}}$ are the sensible and latent cooling demand of the building.

In the realistic cooling system model, the model solves a pychrometric model based on the apparatus dewpoint (ADP) temperature. The current version of BEM considers a constant-volume direct-expansion cooling system, but other system configurations can be added in future versions of the model. At each time step, the supply air temperature and humidity are calculated by satisfying two conditions. First, the supply point in the psychrometric chart (Fig. 2) must be contained in the line connecting the mixing point and the ADP point. Second, the supply temperature should meet the sensible energy demand of the building (Eq. 9). If the energy demand of the building is greater than the system capacity, the system capacity is used to calculate the supply temperature.

The system capacity $\left(Q_{\text {cap,sys }}\right)$ is calculated from the nominal system capacity multiplied by a coefficient that depends on outdoor and indoor conditions (see Appendix A). The electricity consumption of the cooling coil $\left(Q_{\mathrm{HVAC} \text {,sys }}\right)$ is calculated by the following expression:

$Q_{\mathrm{HVAC}, \mathrm{sys}}=Q_{\mathrm{cap}, \mathrm{sys}} \mathrm{PLR} f_{\mathrm{PLR}} / \mathrm{COP}$,

where PLR is the part-load ratio, calculated as the fraction between the energy supplied and the system capacity, and $f_{\text {PLR }}$ is a coefficient that depends on the PLR and accounts for the loss of the system efficiency due to part-load performance. The actual COP of the system is calculated from the nominal COP (provided by the user) multiplied by a coefficient that depends on outdoor and indoor conditions (see Appendix A).

\subsubsection{Heating system}

The current version of BEM considers a fuel-combustion heating system. Other heating systems, such as heat pumps, can be added in future versions of the model. The supply air temperature of the heating system is calculated to meet the sensible heating energy demand of the building (Eq. 12). If the energy demand of the building is greater than the heating system capacity, the system capacity is used to calculate the supply temperature.

$T_{\text {sys }}=T_{\text {mix }}+H_{\text {dem, heat }} /\left(\dot{m}_{\text {sys }} c_{\mathrm{p}}\right)$.

The heating system model assumes that the indoor air humidity is not controlled and that the supply air humidity is the same as the mixing humidity (Eq. 8). The energy consumption of the heating system is calculated from the thermal energy exchanged between the heating system and the indoor air $\left(Q_{\text {exch,heat }}\right)$ divided by a constant efficiency $\left(\eta_{\text {heat }}\right)$, provided by the user.

$Q_{\mathrm{HVAC}, \text { heat }}=Q_{\text {exch, heat }} / \eta_{\text {heat }}$. 


\subsubsection{Fan electricity consumption}

The fan electricity consumption is calculated from the following correlation extracted from EnergyPlus documentation (DOE, 2010):

$P_{\text {fan }}=\dot{m}_{\text {sys }} \Delta P_{\text {fan }} \eta_{\text {fan }} / \rho$,

where $\Delta P_{\text {fan }}$ is the fan design pressure increase, predefined as $600 \mathrm{~Pa}$; and $\eta_{\text {fan }}$ is the fan total efficiency, predefined as 0.7 .

\subsubsection{Waste heat emissions}

The waste heat released into the environment by a cooling system is given by:

$Q_{\text {waste, cool }}=Q_{\text {exch, cool }}+Q_{\mathrm{HVAC}, \mathrm{cool}}$,

where $Q_{\text {exch,cool }}$ is the thermal energy exchanged between the cooling system and the indoor air, and $Q_{\mathrm{HVAC} \text {,cool }}$ is the energy consumption of the cooling system (e.g. electricity). The user can specify the sensible-latent split of the waste heat produced by the cooling system, depending on whether the system is air-condensed, water-condensed, or both.

For the heating system, the waste heat flux is related to the energy contained in the combustion gases and is given by:

$Q_{\text {waste, heat }}=Q_{\mathrm{HVAC}, \text { heat }}-Q_{\text {exch,heat }}$,

where $Q_{\mathrm{HVAC} \text {,heat }}$ is the energy consumption of the heating system (e.g. gas).

\subsubsection{Autosize function}

For the realistic model of an HVAC system, BEM requires information about the size of the system. The parameters that determine the size of a system are the rated cooling capacity and the maximum heating capacity. For a constantvolume cooling system, the model also requires its design mass flowrate. This information can be provided to the model manually, or it can be automatically calculated by the autosize function.

The autosize function first calculates the maximum heating capacity by applying a sensible heat balance at the indoor air (Eq. 4), assuming steady-state heat conduction through the enclosure. An equivalent outdoor air temperature is calculated as the average between the design minimum air temperature (provided by the user) and a generic sky temperature $(253 \mathrm{~K})$. The required air flowrate is then obtained from Eq. (17), assuming a supply air temperature of $323 \mathrm{~K}$.

$\dot{m}_{\text {sys,rat }}=\frac{Q_{\text {heat } \text { max }}}{c_{\mathrm{p}}\left(T_{\text {supply }}-T_{\text {heat,target }}\right)}$.

To calculate the rated cooling capacity, the model dynamically simulates the building during four days, between 12 July and 15 July. The rated cooling capacity corresponds to the maximum cooling energy required to maintain indoor set point conditions for the last day of simulation. This dynamic simulation uses a predefined diurnal cycle of outdoor air temperature and incoming solar radiation (see Appendix A). Incoming solar radiation depends on the specific location of the urban area, using the solar zenith angle calculated by the TEB model. Outdoor air humidity, air velocity, and air pressure are considered constant during this simulation.

Once the rated cooling capacity is calculated, the required air flowrate is obtained assuming a supply air temperature of $287 \mathrm{~K}$. The rated air flowrate will be the maximum of those calculated for cooling and for heating conditions.

\section{Model evaluation}

\subsection{Modelling assumptions}

A methodology is proposed to evaluate BEM assumptions. Two models of the same building with different levels of detail are compared by simulating them with EnergyPlus. The first model, which is referred as the detailed model (DM), includes the exact geometry of the building enclosure, defines each building level as a separate thermal zone, and introduces internal heat gains in terms of people, lighting, and equipment. The second model, which is referred as the simplified model (SM), maintains the assumptions of BEM. It considers a square-base building defined as a single thermal zone with internal mass. The building height, verticalto-horizontal building area ratio, roof-to-horizontal building area ratio, glazing ratio, construction configuration of the enclosure (materials and layers), total internal heat gains, and infiltration air flowrate are the same as the DM (Table 1).

To avoid orientation-specific results, DM is simulated for eight different orientations, every $45^{\circ}$, and SM is simulated for two different orientations, rotated $45^{\circ}$ between each other. This is due to the fact that SM has a square base and its four façades are the same. Then, the average results from each set of simulations are compared.

The results presented in this section correspond to a Haussmannian building in Paris (Fig. 3). Figures 4 and 5 represent the daily average and monthly-averaged diurnal cycles, respectively, of heating energy demand in winter and cooling energy demand in summer calculated by the simplified and the detailed EnergyPlus models. Differences in heating and cooling energy demands, computed as root-meansquare error (RMSE) and mean-bias error (MBE) between the SM and the DM, are presented in Table 2. The RMSE of heating energy demand is $0.9 \mathrm{~W} \mathrm{~m}^{-2}$ of floor area, where the average heating energy demand calculated by the DM for the same period is $19.5 \mathrm{~W} \mathrm{~m}^{-2}$. The RMSE of cooling energy demand is $1.4 \mathrm{~W} \mathrm{~m}^{-2}$, where the average for the same period is $9.1 \mathrm{~W} \mathrm{~m}^{-2}$. In this case, the MBE is $0.9 \mathrm{~W} \mathrm{~m}^{-2}$, which indicates that the SM overestimates the cooling energy demand. The error between the two models can be reduced 
Table 1. Simulation parameters used in the comparison between the simplified EnergyPlus model and the detailed EnergyPlus model of a Haussmannian building. Property values represent a typical residential building.

\begin{tabular}{lcc}
\hline Property & Value & Unit \\
\hline Vertical-to-horizontal building area ratio & 3.14 & \\
Building height & 21.50 & $\mathrm{~m}$ \\
Length of the side of the square building plan & 27.36 & $\mathrm{~m}$ \\
Roof-to-horizontal building area ratio & 0.69 & \\
Internal heat gains & 5.58 & $\mathrm{~W} \mathrm{~m}^{-2}$ \\
Radiant fraction of internal heat gains & 0.40 & \\
Latent fraction of internal heat gains & 0.20 & \\
Window solar heat gain coefficient (SHGC) & 0.60 & \\
Window U-factor & 4.95 & $\mathrm{~W} \mathrm{~m}^{-2} \mathrm{~K}^{-1}$ \\
Glazing-to-wall ratio & 0.2 & \\
Floor height & 2.90 & $\mathrm{~m}$ \\
Infiltration & 0.11 & $\mathrm{ACH}$ \\
Ventilation & 0.43 & $\mathrm{ACH}$ \\
Internal mass-to-horizontal building area ratio & 12.83 & \\
Internal thermal mass construction & Concrete $(100 \mathrm{~mm})$ & \\
Indoor thermal set points & $19-24$ & ${ }^{\circ} \mathrm{C}$ \\
\hline
\end{tabular}

Table 2. Root-mean-square error (RMSE), mean-bias error (MBE), and reference value (REF) of the variables compared in each of the three evaluation sections. The reference value of energy and heat fluxes is the average of the energy and heat fluxes for the considered time period. The term urb indicates unit of urban area and the term fl indicates unit of used area of the building.

\begin{tabular}{|c|c|c|c|}
\hline & RMSE & MBE & $\mathrm{REF}$ \\
\hline \multicolumn{4}{|l|}{ Modelling assumptions (Simplified-Detailed) } \\
\hline Heating energy demand $\left(\mathrm{W} \mathrm{m}^{-2} \mathrm{f}\right)$ & 0.9 & 0.4 & 19.5 \\
\hline Cooling energy demand $\left(\mathrm{W} \mathrm{m}^{-2} \mathrm{fl}\right)$ & 1.4 & 0.9 & 9.1 \\
\hline \multicolumn{4}{|l|}{ Model verification (CS-BEM) } \\
\hline Heating energy demand $\left(\mathrm{W} \mathrm{m}^{-2} \mathrm{fl}\right)$ & 0.8 & 0.3 & 5.6 \\
\hline Cooling energy demand $\left(\mathrm{W} \mathrm{m}^{-2} \mathrm{fl}\right)$ & 1.1 & -0.4 & 6.0 \\
\hline Cooling energy consumption $\left(\mathrm{W} \mathrm{m}^{-2} \mathrm{fl}\right)$ & 0.7 & 0.5 & 3.0 \\
\hline Waste heat emissions ( $\mathrm{W} \mathrm{m}^{-2}$ urb) & 9.8 & 6.0 & 50.2 \\
\hline \multicolumn{4}{|l|}{ Model validation (BEM-Observations) } \\
\hline \multicolumn{4}{|l|}{ Case study: Toulouse, France } \\
\hline \multicolumn{4}{|l|}{ Simulation period: $19 \mathrm{Dec}-17 \mathrm{Feb}$} \\
\hline Electricity consumption ( $\left.\mathrm{W} \mathrm{m}^{-2} \mathrm{urb}\right)$ & 5.1 & -2.8 & 30.8 \\
\hline Gas consumption (W m ${ }^{-2}$ urb) & 7.4 & -6.0 & 19.0 \\
\hline Sensible heat flux ( $\left.\mathrm{W} \mathrm{m}^{-2} \mathrm{urb}\right)$ & 21.3 & -9.3 & 46.3 \\
\hline \multicolumn{4}{|l|}{ Simulation period: 19 Jun-18 Aug } \\
\hline Sensible heat flux $\left(\mathrm{W} \mathrm{m}^{-2} \mathrm{urb}\right)$ & 28.1 & -10.8 & 95.4 \\
\hline \multicolumn{4}{|l|}{ Case study: Athens, Greece } \\
\hline \multicolumn{4}{|l|}{ Simulation period: 30 Jun-29 Aug } \\
\hline Indoor air temperature $(\mathrm{K})$ & 1.1 & 0.1 & \\
\hline
\end{tabular}



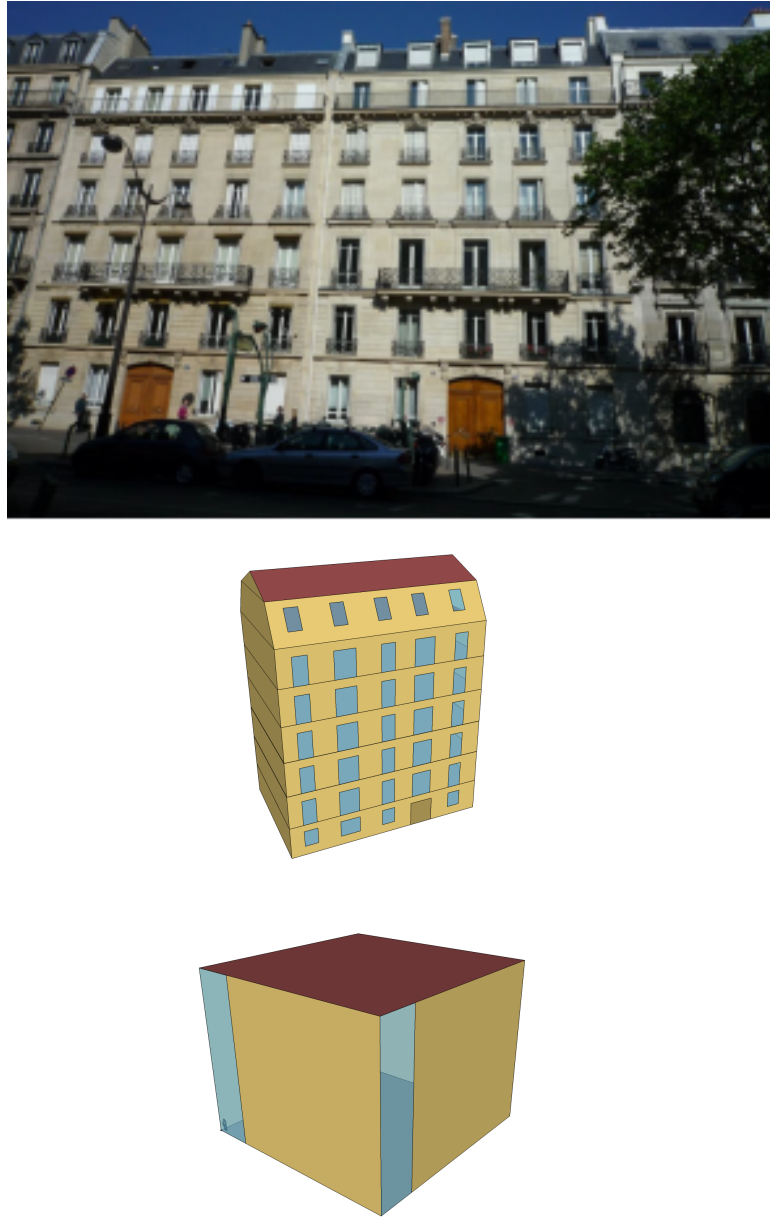

Fig. 3. Image of a Haussmannian building in Paris (top). Representation of the detailed model defined in EnergyPlus (middle). Representation of the simplified model defined in EnergyPlus (bottom).

by simulating the upper floor of the building in the SM as a separate thermal zone. This improvement may be considered in future developments of BEM-TEB.

\subsection{Model verification}

To check that the chosen equations are solved correctly, BEM-TEB is compared to the EnergyPlus-TEB coupled scheme (CS) (Bueno et al., 2011). Table 3 describes the parameters of this case study, which corresponds to the residential urban centre of Toulouse.

Figures 6 and 7 represent the daily average and monthlyaveraged diurnal cycles, respectively, of heating energy demand in winter and cooling energy demand in summer calculated by BEM and the CS. Scores for this comparison are presented in Table 2. The RMSE of heating and cooling energy demand ranges between 0.8 and $1.1 \mathrm{~W} \mathrm{~m}^{-2}$ of floor area, where the average heating and cooling energy demand calculated by the CS is around $6 \mathrm{~W} \mathrm{~m}^{-2}$ for the same period.
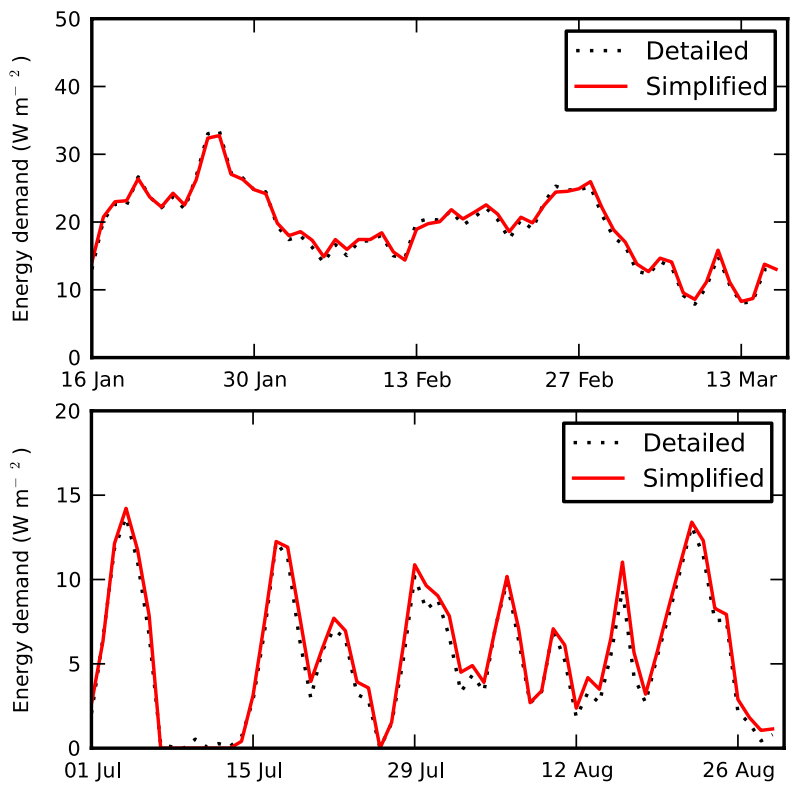

Fig. 4. Daily-average heating (top) and cooling (bottom) energy demand per unit of floor area for winter and summer calculated by the simplified and the detailed EnergyPlus models of a Haussmannian building in Paris.

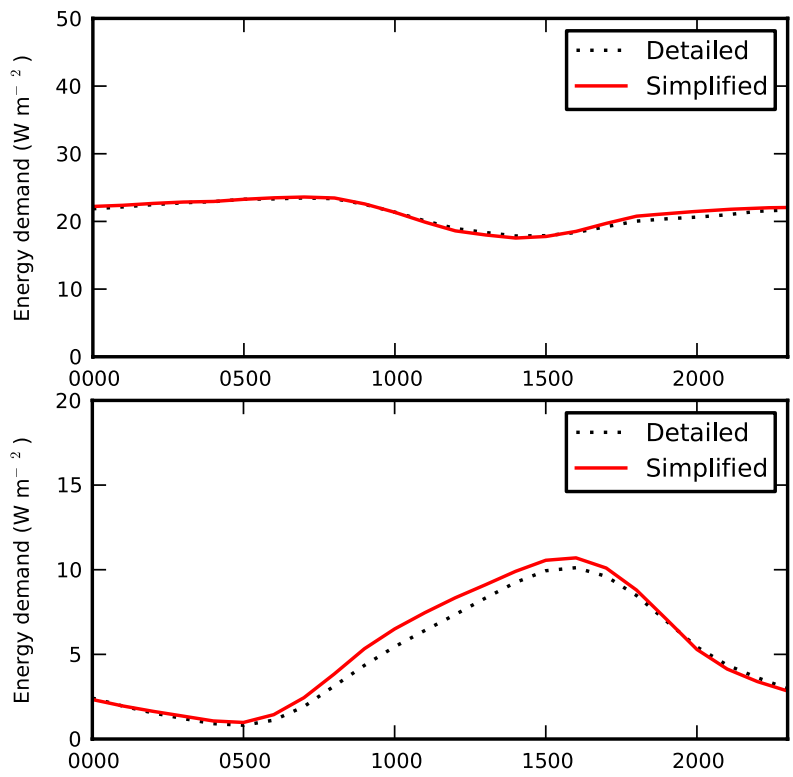

Fig. 5. Monthly-averaged diurnal cycles of heating energy demand between 16 January and 15 February (top) and cooling energy demand between 1 July and 30 July (bottom) per unit of floor area calculated by the simplified and the detailed EnergyPlus models of a Haussmannian building in Paris.

As can be seen, BEM slightly overestimates cooling energy demand in summer (negative MBE) and underestimates heating energy demand in winter (positive MBE) compared to the 
Table 3. Simulation parameters used in the comparison between the coupled scheme and BEM and between BEM and observations. This configuration represents an urban area composed of residential buildings in the dense urban centre of Toulouse, France.

\begin{tabular}{|c|c|c|}
\hline Property & Value & Unit \\
\hline Average building height & 20 & $\mathrm{~m}$ \\
\hline Building density & 0.68 & \\
\hline Vertical-to-horizontal urban area ratio & 1.05 & \\
\hline Roughness length & 2.0 & $\mathrm{~m}$ \\
\hline Anthropogenic heat from traffic & 8.0 & $\mathrm{~W} \mathrm{~m}^{-2}$ urb \\
\hline Glazing-to-wall ratio & 0.3 & \\
\hline Window construction & $\begin{array}{l}\text { Double pane clear glass }(6 \mathrm{~mm} \text { glass with } \\
6 \mathrm{~mm} \text { gap })\end{array}$ & \\
\hline Wall and roof construction & Brick $(30 \mathrm{~cm})$, insulation board $(3 \mathrm{~cm})$ & \\
\hline Road construction & Asphalt, ground & \\
\hline Infiltration/ventilation air flow rate & 0.5 & $\mathrm{ACH}$ \\
\hline Internal heat gains & 5.8 & $\mathrm{~W} \mathrm{~m}^{-2} \mathrm{fl}$ \\
\hline Radiant fraction of internal heat gains & 0.2 & \\
\hline Latent fraction of internal heat gains & 0.2 & \\
\hline Electric fraction of internal heat gains & 0.7 & \\
\hline Cooling system & $\begin{array}{l}\text { Single speed fan on the air side, } \\
\text { with evaporating refrigerant in the coils }\end{array}$ & \\
\hline Heating system & Gas furnace & \\
\hline Indoor thermal set points & $19-24$ & ${ }^{\circ} \mathrm{C}$ \\
\hline Fraction of electric heating systems over gas heating systems & $2 / 3$ & \\
\hline Version of the TEB scheme & Single-layer & \\
\hline
\end{tabular}

CS. This can be explained by the fact that the solar radiation model of the TEB scheme tends to overestimate the solar radiation reaching building façades as compared with the CS.

Figure 8 compares the daily average cooling energy consumption and waste heat emissions of the HVAC system calculated by BEM and the CS. The RMSE of cooling energy consumption is $0.7 \mathrm{~W} \mathrm{~m}^{-2}$ of floor area (Table 2), where the average cooling energy consumption calculated by the CS is $3 \mathrm{~W} \mathrm{~m}^{-2}$ for the same period. A relative error of $20 \%$ in building energy consumption is acceptable given the stateof-the-art of urban canopy models. Grimmond et al. (2011) show that the surface heat flux error of urban canopy models is usually greater than $20 \%$. A similar order of magnitude difference is encountered for the waste heat emissions calculated by both models. The RMSE of waste heat emissions is $9.8 \mathrm{~W} \mathrm{~m}^{-2}$ of urban area, where the average waste heat fluxes for the same period is $50.2 \mathrm{~W} \mathrm{~m}^{-2}$.

\subsection{Model validation}

Field data from two different experiments are used to evaluate BEM-TEB. The first one is the CAPITOUL experiment, carried out in Toulouse (France) from February 2004 to March 2005 (Masson et al., 2008). Measurements of air temperature at street level were carried out simultaneously at 27 locations inside and at the periphery of the city. In this comparison, the observations from the station located next to the Monoprix building, in the dense urban centre of Toulouse, is used. Forcing information, including sensible heat fluxes, was also measured at the top of the Monoprix building, 47.5 $\mathrm{m}$ above the ground. In addition, a city-scale inventory of electricity and natural gas energy consumption of buildings was conducted. Anthropogenic heat fluxes from traffic and building energy uses were obtained from the residual of the surface energy balance (SEB) equation (Oke, 1988). A detailed description of the inventory approach and the residual method is presented in Pigeon et al. (2007).

Table 3 presents the model set-up for this case study, which is the same as in Sect. 3.2. A number of modelling 
Table 4. Simulation parameters used in the comparison between BEM and observations. This configuration represents an urban area composed of residential buildings in the Egaleo neighbourhood in Athens, Greece.

\begin{tabular}{|c|c|c|}
\hline Property & Value & Unit \\
\hline Average building height & 9.5 & $\mathrm{~m}$ \\
\hline Building density & 0.64 & \\
\hline Vertical-to-horizontal urban area ratio & 1.05 & \\
\hline Roughness length & 0.95 & $\mathrm{~m}$ \\
\hline Anthropogenic heat from traffic & 8.0 & $\mathrm{~W} \mathrm{~m}^{-2}$ urb \\
\hline Glazing-to-wall ratio & 0.25 & \\
\hline Window construction & Single pane clear glass $(6 \mathrm{~mm})$ & \\
\hline Wall and roof construction & Concrete $(30 \mathrm{~cm})$ & \\
\hline Road construction & Asphalt, ground & \\
\hline Infiltration air flowrate & 0.5 & $\mathrm{ACH}$ \\
\hline Internal heat gains & 4.0 & $\mathrm{~W} \mathrm{~m}^{-2} \mathrm{fl}$ \\
\hline Radiant fraction of internal heat gains & 0.2 & \\
\hline Latent fraction of internal heat gains & 0.2 & \\
\hline Electric fraction of internal heat gains & 0.7 & \\
\hline HVAC system & None & \\
\hline Natural ventilation & Activated & \\
\hline Shading devices & $\begin{array}{l}\text { Exterior shades; solar radiation on } \\
\text { windows for which shades are ON: } \\
250 \mathrm{Wm}-2 ; \text { solar transmittance of } \\
\text { shades: } 0.3\end{array}$ & \\
\hline
\end{tabular}

assumptions were made given the lack of detailed information about the buildings of the site. From those, the most relevant are the internal heat gain value, the wall insulation thickness, and the fraction between electric and gas heating systems. A justification of the values chosen is presented in Bueno et al. (2011).

Electricity consumption, natural gas consumption, and anthropogenic heat data from the CAPITOUL experiment were compared to BEM-TEB simulation results for two months in winter (Fig. 9). Electricity and natural gas consumption computed as MBE and RMSE between BEM and observations are presented in Table 2. The RMSE of electricity consumption is $5.1 \mathrm{~W} \mathrm{~m}^{-2}$, averaged over the urban area, where the average electricity consumption calculated by the model is $30.8 \mathrm{~W} \mathrm{~m}^{-2}$. A similar RMSE of gas consumption is obtained, $7.4 \mathrm{~W} \mathrm{~m}^{-2}$. It can be seen that BEM-TEB slightly underpredicts electricity and gas consumption in this comparison.

Observations of sensible heat fluxes were also compared with BEM-TEB simulation results (Fig. 10). For the summer case, two scenarios are considered. In the first one, we assume that there are no waste heat emissions associated with cooling systems. This represents a situation in which the use of air-conditioning systems in the urban area under study is negligible. In the second scenario, all buildings are assumed to have conditioned spaces and waste heat emissions from cooling equipment are released into the environment. Fig. 10 shows that, for certain days, the simulation with cooling systems presents a better agreement with observations than the simulation without cooling systems. This suggests that there might be a certain number of buildings with operating air-conditioning systems in Toulouse. The RMSE of sensible heat fluxes between the simulation without cooling systems (our first hypothesis) and observations in summer is $28.1 \mathrm{~W} \mathrm{~m}^{-2}$, where the average sensible heat flux calculated by the model for the same period is $95.4 \mathrm{~W} \mathrm{~m}^{-2}$. A lower RMSE is obtained in winter, $21.3 \mathrm{~W} \mathrm{~m}^{-2}$, although the average sensible heat flux is also lower in this period.

The second experiment was carried out in Athens (Greece) between May and September 2009, framed in the European project BRIDGE (Synnefa et al., 2010). Indoor air temperatures were measured in ten representative residential buildings of the Egaleo neighbourhood. Simultaneous outdoor air temperature measurements are also available. Most of the 

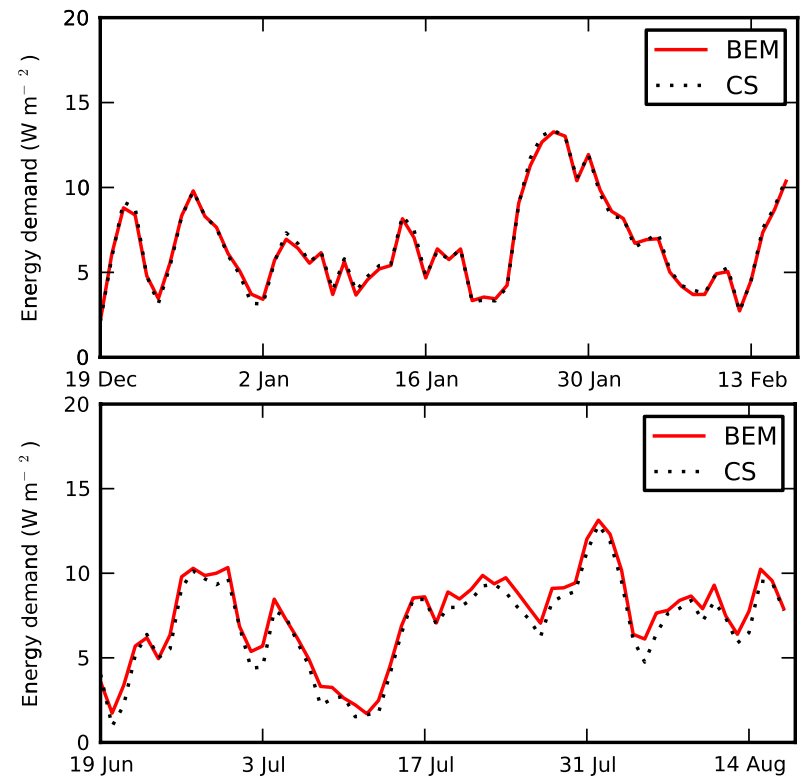

Fig. 6. Daily-average heating (top) and cooling (bottom) energy demand per unit of floor area for winter and summer calculated by the coupled scheme and by BEM-TEB for the dense urban centre of Toulouse.
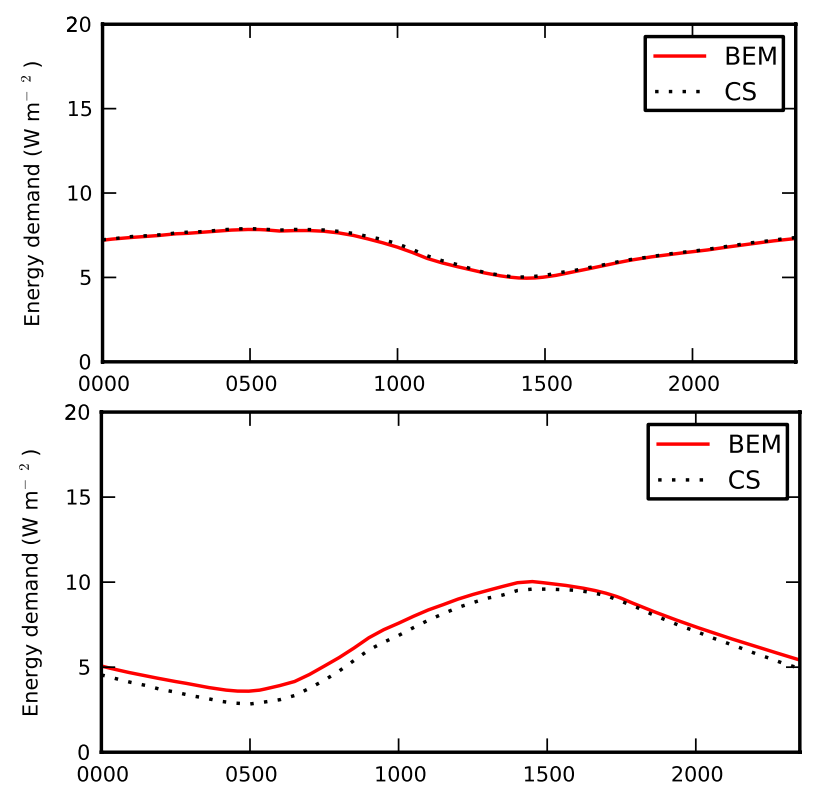

Fig. 7. Monthly-averaged diurnal cycles of heating energy demand between 1 January and 30 January (top) and cooling energy demand between 1 July and 30 July (bottom) per unit of floor area calculated by the coupled scheme and by BEM-TEB for the dense urban centre of Toulouse.

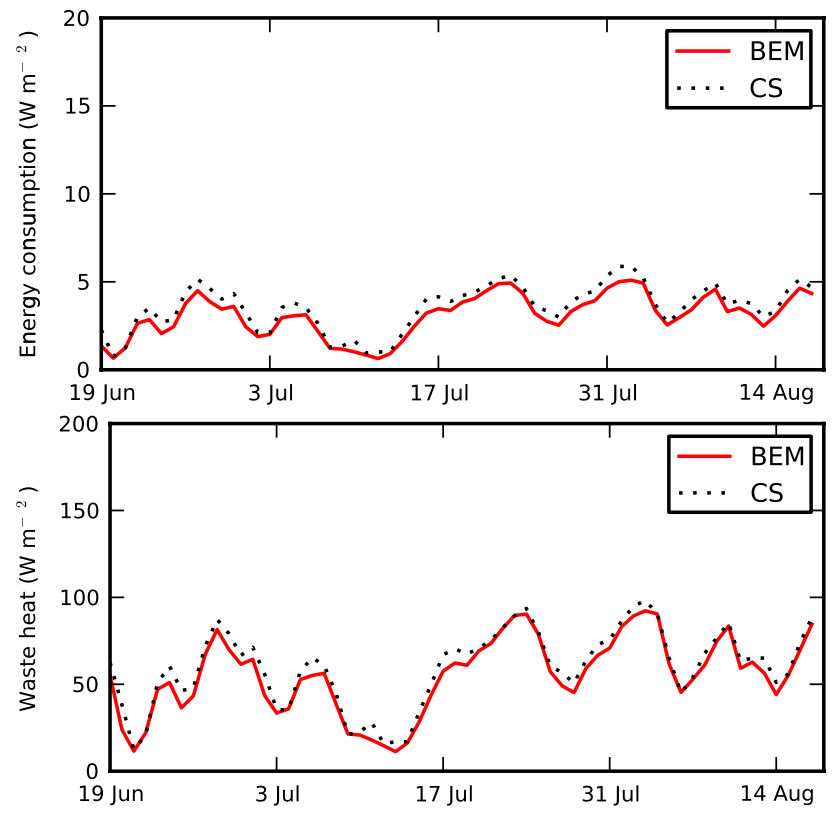

Fig. 8. Daily-average cooling energy consumption per unit of floor area (top) and waste heat emissions per unit of urban area (bottom) calculated by the coupled scheme and by BEM-TEB for the dense urban centre of Toulouse.
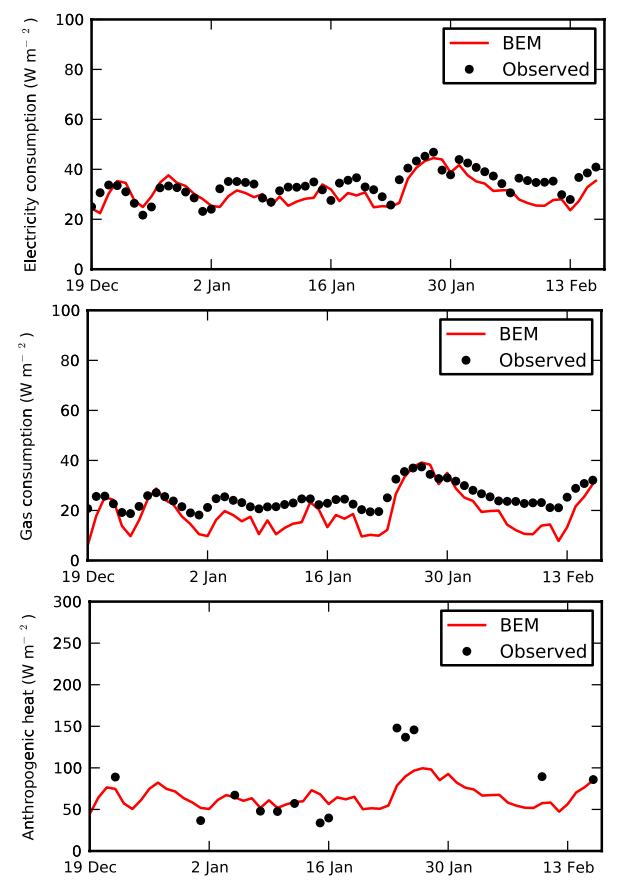

Fig. 9. Daily-average electricity consumption (top), natural gas consumption (middle) and anthropogenic heat (bottom) per unit of urban area from observations and calculated by BEM-TEB in winter for the dense urban centre of Toulouse. 

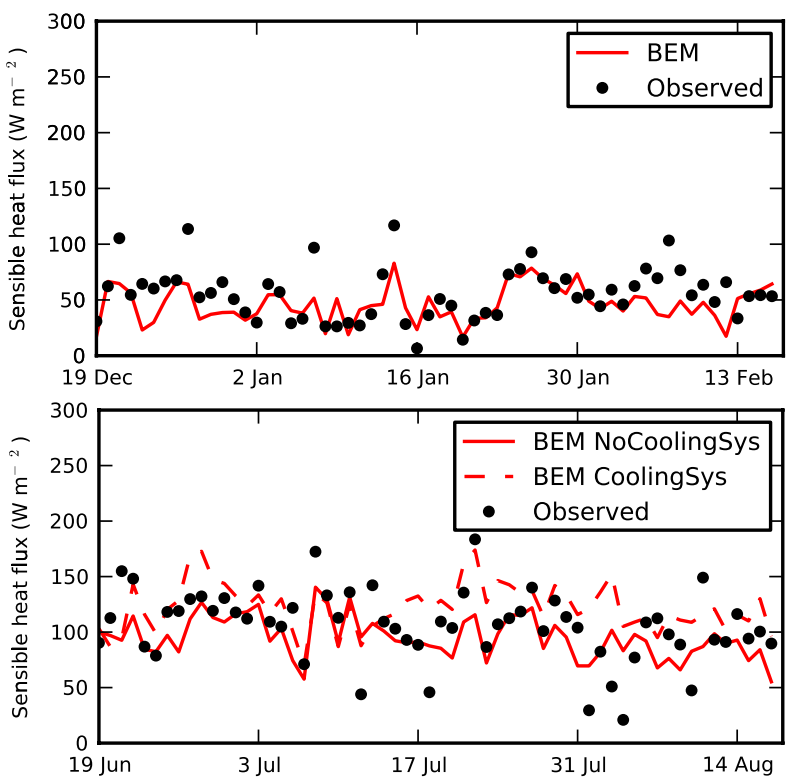

Fig. 10. Daily-average sensible heat flux per unit of urban area from observations and calculated by BEM-TEB in winter (top) and in summer (bottom) for the dense urban centre of Toulouse. For the summer case, BEM-TEB simulations consider the presence or not of operating air-conditioning systems in the urban area.
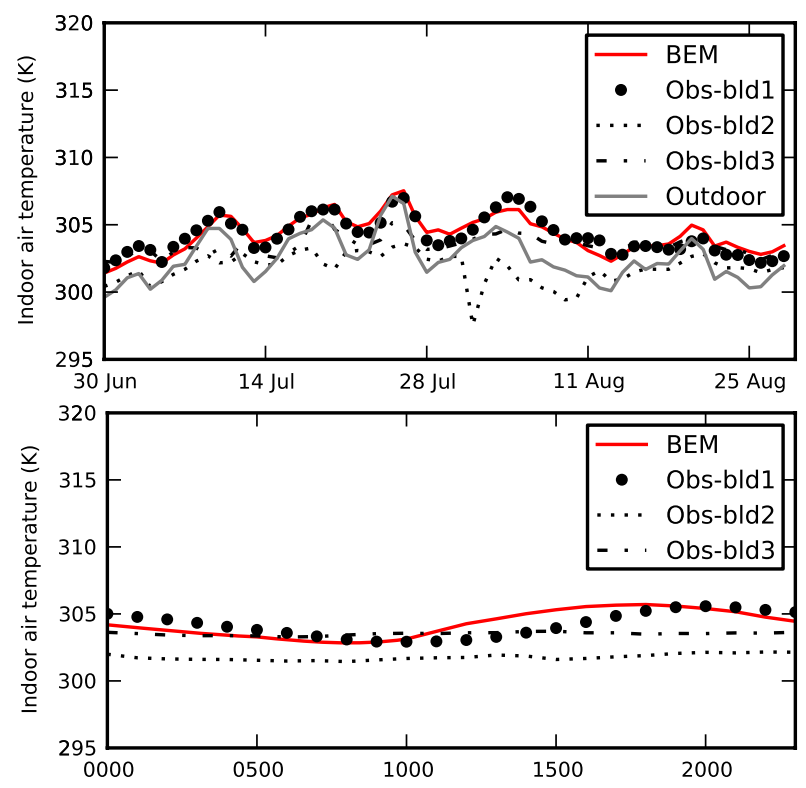

Fig. 11. Daily-average (top) and monthly-averaged diurnal cycle (bottom) of indoor air temperature from observations and calculated by BEM-TEB from 30 June to 30 August for the Egaleo neighbourhood of Athens. Observations correspond to three different residential buildings. Daily-average outdoor air temperatures are also represented (top).
Table A1. Nomenclature.

\begin{tabular}{|c|c|c|}
\hline Symbol & Designation & Unit \\
\hline A & Area & $\mathrm{m}^{2}$ \\
\hline $\mathrm{COP}$ & Coefficient of performance of an HVAC system & - \\
\hline$c_{\mathrm{p}}$ & Air specific heat & $\mathrm{J} \mathrm{kg}^{-1} \mathrm{~K}^{-1}$ \\
\hline$C_{\mathrm{p}}$ & Pressure coefficient & - \\
\hline$f$ & Fraction & _- \\
\hline$F$ & View factor & - \\
\hline$g$ & Gravity acceleration & $\mathrm{ms}^{-2}$ \\
\hline GR & Glazing ratio & - \\
\hline$h$ & Heat transfer coefficient & $\mathrm{W} \mathrm{m} \mathrm{m}^{-2} \mathrm{~K}^{-1}$ \\
\hline$h_{\text {win }}$ & Opening height for natural ventilation & $\mathrm{m}$ \\
\hline$H$ & Sensible heat & $\mathrm{W} \mathrm{m}^{-2}$ \\
\hline$K_{\text {sol }}$ & Solar constant & $\mathrm{Wm}^{-2}$ \\
\hline$l_{\mathrm{v}}$ & Water condensation heat & $\mathrm{J} \mathrm{kg}^{-1}$ \\
\hline LE & Latent heat & $\mathrm{Wm}^{-2}$ \\
\hline$\dot{m}$ & Air mass flowrate & $\mathrm{kg}^{3} \mathrm{~s}^{-1}$ \\
\hline$N_{\mathrm{fl}}$ & Number of floors in a building & - \\
\hline$P$ & Electric power & $\mathrm{W}$ \\
\hline PLR & Part-load ratio & - \\
\hline$q$ & Specific humidity & $\mathrm{kg} \mathrm{kg}^{-1}$ \\
\hline$Q$ & Heat flux & $\mathrm{W} \mathrm{m}^{-2}$ \\
\hline$S^{\downarrow}$ & Incoming solar radiation & $\mathrm{W} \mathrm{m}^{-2}$ \\
\hline$t$ & Time & $\mathrm{s}$ \\
\hline$T$ & Temperature & ${ }^{\circ} \mathrm{C}, \mathrm{K}$ \\
\hline$U$ & Mean air velocity & $\mathrm{ms}^{-1}$ \\
\hline$V$ & Volume & $\mathrm{m}^{3}$ \\
\hline$\dot{V}$ & Air volume flowrate & $\mathrm{m}^{3} \mathrm{~s}^{-1}$ \\
\hline $\mathrm{VH}_{\text {urb }}$ & Vertical-to-horizontal urban area ratio & - \\
\hline$X_{\text {mix }}$ & Mixing ratio & - \\
\hline Z & Solar zenith angle & $\mathrm{rad}$ \\
\hline$\rho_{\mathrm{bld}}$ & Building density & - \\
\hline$\varepsilon$ & Surface emissivity & - \\
\hline$\sigma$ & Stefan-Boltzmann constant & $\mathrm{W} \mathrm{m}^{-2} \mathrm{~K}^{-4}$ \\
\hline$\rho$ & Air density & $\mathrm{kg} \mathrm{m}^{-3}$ \\
\hline$\tau$ & Transmittance & - \\
\hline$\eta$ & Efficiency & - \\
\hline$\varphi$ & Performance curve of an cooling system & - \\
\hline
\end{tabular}

analysed buildings were constructed between 1950 and 1980 and were made of reinforced concrete with poor or no insulation and single-pane windows. Cooling systems are generally absent and buildings are naturally ventilated. Air temperature sensors were placed in the centre of the living room of an intermediate floor. Three of the ten buildings share the same input parameters of BEM (Table 4) and are used in this comparison. Reasonable modelling assumptions were made in terms of shadowing and natural ventilation, given the lack of detailed information about the buildings of the site.

The measured indoor air temperatures are compared to BEM simulation results for two months in summer (Fig. 11). Indoor air temperatures in naturally-ventilated buildings are very sensitive to occupant behaviour (occupation schedules, shades and window operation, etc.); thus, even if the buildings have similar parameters in terms of the simulation, their performance can be significantly different. As can be seen, BEM is able to reproduce the daily average evolution, as well as the daily cycle amplitude, of indoor air temperatures measured in building 1 with an RMSE of $1.1 \mathrm{~K}$ (Table 2); but it overestimates the indoor air temperatures measured in building 2 and, to a lesser extent, those measured in building 3 . This can be explained by the fact that building 1 performs 
Table A1. Continued.

\begin{tabular}{ll}
\hline Symbol & Designation \\
\hline Subscripts & \\
\hline bld & Building \\
can & Urban canyon \\
cap & HVAC system capacity \\
cd & Conduction \\
cool & Cooling \\
cv & Convection \\
dem & Energy demand \\
exch & Energy exchanged between the system and the building \\
fl & Floor \\
heat & Heating \\
HVAC & HVAC system energy consumption \\
ig & Internal heat gains \\
in & Indoor air \\
inf & Infiltration \\
lat & Latent \\
m & Building internal thermal mass \\
mix & HVAC mixing conditions \\
nt & Natural ventilation \\
rat & Rated conditions \\
rd & Radiation \\
sens & Sensible heat \\
si & Interior surface \\
sol & Solar radiation \\
supply & HVAC system supply conditions \\
sys & HVAC system \\
urb & Outdoor air \\
vent & Ventilation \\
w & Walls \\
waste & Waste heat from HVAC systems \\
wi & Inner layer of wall \\
win & Windows \\
\hline &
\end{tabular}

more in phase with the outdoor environment than building 2, which means that building 1 has less fluctuations of internal heat gains and human building operation and, therefore, can be better captured by the simulation. Compared to building 1 , BEM slightly overestimates the indoor air temperature during daytime (positive MBE), probably because BEM does not consider occupation schedules, which would decrease internal heat gains during working hours.

\section{Conclusions}

A new building energy model (BEM) integrated in the TEB scheme is developed in order to represent the building effects on urban climate and to estimate the energy consumption of buildings at city or neighbourhood scale. It includes specific models for active and passive building systems, which allows comparing the performance of different energy efficiency strategies in an urban context. The model introduces simplifying assumptions in order to keep the computational cost of simulations low. The increase in computational time with respect to the previous TEB model is $21 \%$, which is acceptable given that one-year simulation for one location with $300 \mathrm{~s}$ time step is about $100 \mathrm{~s}$ for 1 processor $(2.4 \mathrm{Ghz})$.
An evaluation of the model composed of three steps (modelling assumptions, verification, and validation) has been presented. BEM is able to reproduce the results of a more sophisticated building energy program, such as EnergyPlus, and the comparison with field data shows reasonable agreement. Next steps include extending the evaluation to other building configurations and climates; introducing new HVAC configurations, such as heat-pumps or variable-air-volume systems; and improving the current models of shadowing devices and natural ventilation systems.

\section{Appendix A}

\section{Heat balance method}

The convection term of Eq. (1) is calculated from:

$Q_{\mathrm{cv}}=h_{\mathrm{cv}}\left(T_{\mathrm{si}}-T_{\mathrm{in}}\right)$,

where $T_{\mathrm{si}}$ and $T_{\mathrm{in}}$ are the temperature of an interior surface and of the indoor air, respectively. The convective heat transfer coefficient has the following values: $h_{\mathrm{cv}}=3.076 \mathrm{~W} \mathrm{~m}^{-2} \mathrm{~K}^{-1}$ for a vertical surface; $h_{\mathrm{cv}}=$ $0.948 \mathrm{~W} \mathrm{~m}^{-2} \mathrm{~K}^{-1}$ for a horizontal surface with reduced convection (floor surface with $T_{\mathrm{si}}<T_{\mathrm{in}}$ and ceiling surface with $\left.T_{\mathrm{si}}>T_{\mathrm{in}}\right)$; and $h_{\mathrm{cv}}=4.040 \mathrm{~W} \mathrm{~m}^{-2} \mathrm{~K}^{-1}$ for a horizontal surface with enhanced convection. The radiation term is calculated as:

$Q_{\mathrm{rd} 1-2}=h_{\mathrm{rd}} F_{1-2}\left(T_{\mathrm{s}, 1}-T_{\mathrm{s}, 2}\right)$,

where $h_{\text {rd }}$ is a radiative heat transfer coefficient and $F_{1-2}$ is the configuration factor between surfaces 1 and 2 . Radiative heat transfer coefficients are calculated as:

$h_{\mathrm{rd}}=4 \varepsilon^{2} \sigma T_{\mathrm{rd}}^{3}$,

where $\varepsilon=0.9$ is the surface emissivity, $\sigma$ is the StefanBoltzmann constant, and $T_{\mathrm{rd}}$ is an average surface temperature. View factors $(F)$ between surfaces are given by:

$$
\begin{aligned}
& F_{\mathrm{fl}-\mathrm{m}}=\left((h / w)_{\mathrm{fl}}^{2}+1\right)^{1 / 2}-(h / w)_{\mathrm{fl}}, \\
& F_{\mathrm{fl}-\mathrm{wi}}=\left(1-F_{\mathrm{fl}-\mathrm{m}}\right)(1-\mathrm{GR}), \\
& F_{\mathrm{fl}-\mathrm{win}}=\left(1-F_{\mathrm{fl}-\mathrm{m}}\right) \mathrm{GR}, \\
& F_{\mathrm{aux}}=\left((h / w)_{\mathrm{fl}}+1-\left((h / w)_{\mathrm{fl}}^{2}+1\right)^{1 / 2}\right) /(h / w)_{\mathrm{fl}}, \\
& F_{\mathrm{wi}-\mathrm{m}}=F_{\mathrm{win}-\mathrm{m}}=F_{\mathrm{aux}}\left(2 N_{\mathrm{fl}}-2\right) /\left(2 N_{\mathrm{fl}}\right), \\
& F_{\mathrm{wi}-\mathrm{win}}=\left(1-F_{\mathrm{aux}}\right) \mathrm{GR}, \\
& F_{\mathrm{wi}-\mathrm{fl}}=F_{\mathrm{win}-\mathrm{fl}}=F_{\text {aux }} / 2 N_{\mathrm{fl}}, \\
& F_{\mathrm{win}-\mathrm{wi}}=\left(1-F_{\text {aux }}\right)(1-\mathrm{GR}),
\end{aligned}
$$



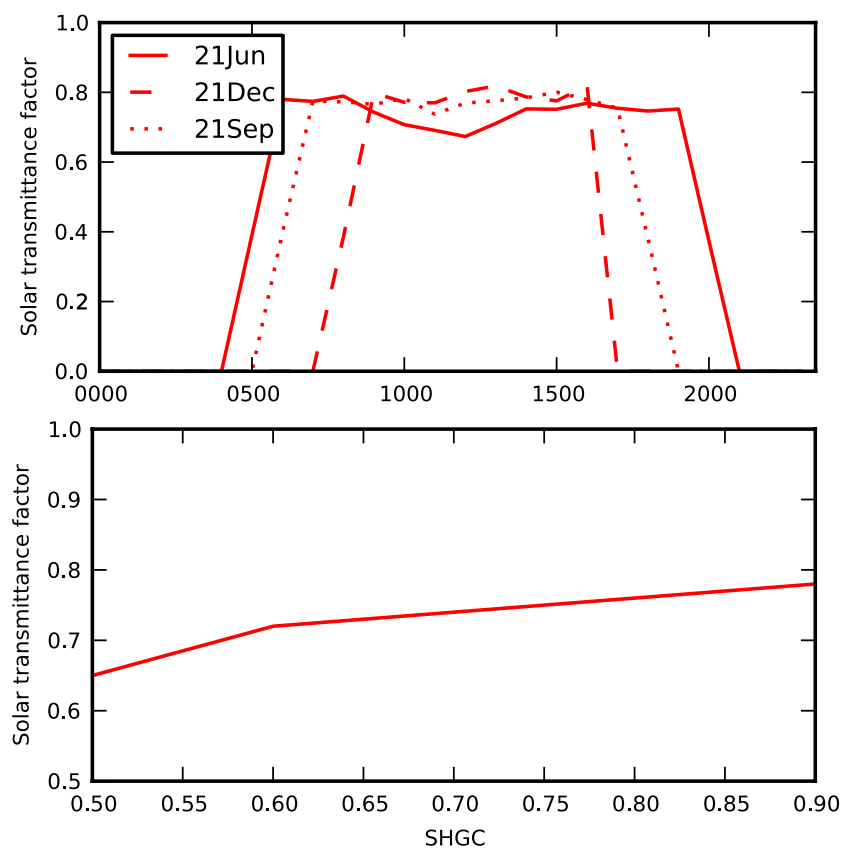

Fig. A1. Diurnal cycle of the solar transmittance factor of a window with a $\mathrm{SHGC}=0.8$ (top) and daytime-average solar transmittance factor for different SHGC (bottom). The solar transmittance factor is defined as the ratio between the average of the solar transmittances for different window orientations and the SHGC. In the first graph, three characteristic days of the year are represented, the two solstices and an equinox.

$F_{\mathrm{m}-\mathrm{wi}}=F_{\mathrm{wi}-\mathrm{m}} A_{\mathrm{wi}} / A_{\mathrm{m}}$,

$F_{\mathrm{m}-\text { win }}=F_{\text {win }-\mathrm{m}} A_{\text {win }} / A_{\mathrm{m}}$,

and

$F_{\mathrm{m}-\mathrm{fl}}=F_{\mathrm{fl}-\mathrm{m}} / A_{\mathrm{m}}$,

where the subscripts $\mathrm{fl}, \mathrm{m}$, wi, and win represent floor, internal mass, internal wall, and window, respectively; GR is the glazing ratio of the building; and $(h / w)_{\mathrm{fl}}$ represents the aspect ratio of one building level.

\section{A1 Solar heat transmission}

Generally, the solar heat transmitted through windows depends on the angle of incidence of the sun. However, based on simulations with EnergyPlus, we can show that the solar transmittance is proportional to the window SHGC for an average-oriented canyon. The Solar Transmittance Factor (STF) is defined as the ratio between the average of the solar transmittances for different window orientations and the SHGC.

A series of simulations were carried out with EnergyPlus for eight different orientations of a window in intervals of $45^{\circ}$. Three characteristic days in Toulouse, the two solstices and an equinox, were simulated for different values of the SHGC. Fig. A1a represents the diurnal cycle of STF for windows with a $\mathrm{SHGC}=0.8$. Fig. A1b shows the dependence of the daytime STF on the SHGC. From this analysis, we conclude that a constant STF of $0.75 \pm 0.03$ can be considered for an average-oriented window with a SHGC between 0.6 and 0.9 .

\section{A2 Natural ventilation}

The natural ventilation module first compares indoor and outdoor air temperatures. If $T_{\mathrm{in}}>T_{\mathrm{urb}}+1 \mathrm{~K}$, the modules estimates a natural ventilation potential, by calculating the indoor air temperature with and without natural ventilation, $T_{\text {open }}$ and $T_{\text {close }}$, respectively.

The conditions are considered favourable for natural ventilation if $T_{\text {open }}<T_{\text {cool,target }}, T_{\text {open }}<T_{\text {close, }}$ and $T_{\text {open }}>$ $T_{\text {heat, target }}+4 \mathrm{~K}$.

The natural ventilation air flowrate per unit width $\left(\dot{V}_{\mathrm{nv}}\right)$ is calculated from the following equation for a single opening with bidirectional flow (Truong, 2012):

$$
\begin{aligned}
& \dot{V}_{\mathrm{nv}}=\frac{1}{3}\left[g \frac{T_{\text {in }}-T_{\text {urb }}}{T_{\text {in }}}\right]^{1 / 2} \\
& {\left[h_{\text {win }}+\frac{T_{\text {in }}}{g\left(T_{\text {in }}-T_{\text {urb }}\right)} \frac{1}{2} U_{\text {ref }}^{2} \Delta C_{\mathrm{p}}\right]^{3 / 2}}
\end{aligned}
$$

where $h_{\text {win }}$ is the window height, $\Delta C_{\mathrm{p}}$ is the pressure coefficient difference between the windward and the leeward sides of the building, and $U_{\text {ref }}$ is the average air velocity where the pressure coefficients are measured.

\section{A3 Cooling system}

BEM accounts for the dependence of a cooling system on outdoor and indoor conditions, through the definition of characteristic performance curves (DOE, 2010). The total cooling capacity is calculated from the rated capacity, modified by the following curve:

$\varphi_{Q}=A_{1}+B_{1} T_{\mathrm{wb}, \mathrm{i}}+C_{1} T_{\mathrm{wb}, \mathrm{i}}^{2}+D_{1} T_{\mathrm{c}, \mathrm{i}}+E_{1} T_{\mathrm{c}, \mathrm{i}}^{2}+F_{1} T_{\mathrm{wb}, \mathrm{i}} T_{\mathrm{c}, \mathrm{i},}$

where $T_{\mathrm{wb}, \mathrm{i}}\left({ }^{\circ} \mathrm{C}\right)$ is the wet-bulb temperature of the air entering the cooling coil and $T_{\mathrm{c}, \mathrm{i}}\left({ }^{\circ} \mathrm{C}\right)$ is the dry-bulb outdoor air temperature, in an air-cooled condenser (wet-bulb outdoor air temperature in an evaporative condenser). The actual COP of the system is calculated from the nominal COP, divided by the following curve:

$\varphi_{\mathrm{COP}}=A_{2}+B_{2} T_{\mathrm{wb}, \mathrm{i}}+C_{2} T_{\mathrm{wb}, \mathrm{i}}^{2}+D_{2} T_{\mathrm{c}, \mathrm{i}}+E_{2} T_{\mathrm{c}, \mathrm{i}}^{2}+F_{2} T_{\mathrm{wb}, \mathrm{i}} T_{\mathrm{c}, \mathrm{i} .}$

The coefficients used in Eqs. (A16) and (A17) are the default ones used by EnergyPlus when a single-speed directexpansion cooling system is defined: $A_{1}=0.942587793$, $B_{1}=0.009543347, C_{1}=0.00068377, D_{1}=-0.011042676$, $E_{1}=0.000005249, F_{1}=-0.00000972, A_{2}=0.342414409$, $B_{2}=0.034885008, C_{2}=-0.0006237, D_{2}=0.004977216$, $E_{2}=0.000437951$, and $F_{2}=-0.000728028$. 
The coefficient $f_{\text {PLR }}$ of Eq. (11) is given by:

$f_{\mathrm{PLR}}=0.85+0.15 \mathrm{PLR}$,

where PLR is the part-load ratio, calculated as the fraction between the energy supplied and the system capacity.

\section{A4 Autosize function}

The rated cooling capacity is calculated by dynamically simulating the building with predefined diurnal cycles of outdoor air temperature and incoming solar radiation. The diurnal cycle of outdoor air temperature has a maximum defined by the user and an amplitude of $10.7 \mathrm{~K}$. The evolution is sinusoidal according to the following equation:

$T_{\text {can }}=T_{\text {size } \max }-5.35+5.35 \sin (2 \pi(t+57600) / 86400)$.

The solar radiation at each time step is given by:

$S^{\downarrow}=K_{\mathrm{sol}} D_{\mathrm{corr}} \cos (Z)$,

where $\quad K_{\text {sol }}=1367 \mathrm{~W} \mathrm{~m}^{-2}, \quad D_{\text {corr }}=1+0.0334 \cos$ $\left(0.01721 D_{\text {julian }}-0.0552\right)$, and $Z$ is the solar zenith angle; and where $D_{\text {julian }}$ is the Julian day of the year.

Acknowledgements. This study has received funding from the French National Research Agency under the MUSCADE project referenced as ANR-09-VILL-003, from the European Community's Seventh Framework Programme (FP7/2007-2013) under grant agreement no. 211345 (BRIDGE Project). It has also been partially funded by the Singapore National Research Foundation through the Singapore-MIT Alliance for Research and Technology (SMART) Centre for Environmental Sensing and Modelling (CENSAM). We would also like to thank Synnefa from NKUA for providing the data for the Egaleo case study.

Edited by: S. Easterbrook

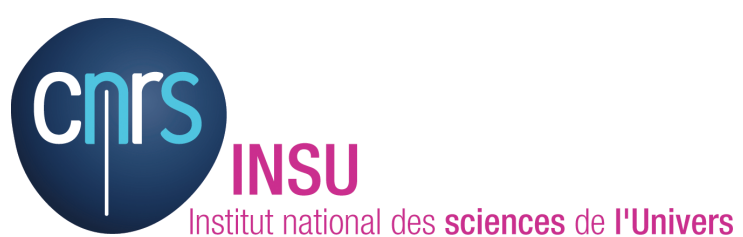

The publication of this article is financed by CNRS-INSU.

\section{References}

Adnot, J.: Energy Efficiency and Certification of Central Air Conditioners (EECCAC), ARMINES, Paris, France, 2003.

Bueno, B., Norford, L., Pigeon, G., and Britter, R.: Combining a detailed building energy model with a physically-based urban canopy model, Bound.-Lay. Meteorol., 140, 471-489, 2011.

Bueno, B., Norford, L., Pigeon, G., and Britter, R.: A resistancecapacitance network model for the analysis of the interactions between the energy performance of buildings and the urban climate, Build. Environ., 54, 116-125, 2012.
Crawley, D. B., Lawrie, L. K., Winkelmann, F. C., Buhl, W. F., Huang, Y. J., Pedersen, C. O., Strand, R. K., Liesen, R. J., Fisher, D. E., Witte, M. J., and Glazer, J.: EnergyPlus: creating a newgeneration building energy simulation program, Energy Build., 33, 319-331, 2001.

de Munck, C., Pigeon, G., Masson, V., Meunier, F., Bousquet, P., Trmac, B., Merchat, M., Poeuf, P., and Marchadier, C.: How much can air conditioning increase air temperatures for a city like Paris, France, Int. J. Climatol., doi:10.1002/joc.3415, 2012. DOE: EnergyPlus Engineering Reference, EnergyPlus, 2010.

Grimmond, C. S. B., Blackett, M., Best, M. J., Baik, J.-J., Belcher, S. E., Beringer, J., Bohnenstengel, S. I., Calmet, I., Chen, F., Coutts, A., Dandou, A., Fortuniak, K., Gouvea, M. L., Hamdi, R., Hendry, M., Kanda, M., Kawai, T., Kawamoto, Y., Kondo, H., Krayenhoff, E. S., Lee, S.-H., Loridan, T., Martilli, A., Masson, V., Miao, S., Oleson, K., Ooka, R., Pigeon, G., Porson, A., Ryu, Y.-H., Salamanca, F., Steeneveld, G., Tombrou, M., Voogt, J. A., Young, D. T., and Zhang, N.: Initial results from Phase 2 of the international urban energy balance model comparison, Int. J. Climatol., 31 , 244-272, 2011.

Hamdi, R. V., and Masson, V.: Inclusion of a drag approach in the Town Energy Balance (TEB) Scheme: Offline 1-D validation in a street canyon, J. Appl. Meteorol. Climatol., 47, 2627-2644, 2008.

Ihara, T., Kikegawa, Y., Asahi, K., Genchi, Y., and Kondo, H.: Changes in year-round air temperature and annual energy consumption in office building areas by urban heat-island countermeasures and energy-saving measures, Appl. Energy, 85, 12-25, 2008.

Kikegawa, Y., Genchi, Y., Yoshikado, H., and Kondo, H.: Development of a numerical simulation system for comprehensive assessments of urban warming countermeasures including their impacts upon the urban building's energy-demands, Appl. Energy, 76, 449-66, 2003.

Kikegawa, Y., Genchi, Y., Kondo, H., and Hanaki, K.: Impacts of city-block-scale countermeasures against urban heatisland phenomena upon a building's energy-consumption for airconditioning, Appl. Energy, 83, 649-668, 2006.

Kondo, H. and Kikegawa, Y.: Temperature variation in the urban canopy with anthropogenic energy use, Pure Appl. Geophys., 160, 317-324, 2003.

Lemonsu, A., Grimmond, C. S. B., and Masson, V.: Modelling the surface energy balance of the core of an old Mediterranean city: Marseille, J. Appl. Meteorol., 43, 312-327, 2004.

Lemonsu, A., Bélair, S., Mailhot, J., and Leroyer, S.: Evaluation of the Town Energy Balance Model in Cold and Snowy Conditions during the Montreal Urban Snow Experiment 2005, J. Appl. Meteorol. Climatol., 49, 346-362, 2010.

Masson, V.: A physically-based scheme for the urban energy budget in atmospheric models, Bound.-Lay. Meteorol., 94, 357-397, 2000.

Masson, V., Grimmond, C. S. B., and Oke, T. R.: Evaluation of the Town Energy Balance (TEB) scheme with direct measurements from dry districts in two cities, J. Appl. Meteorol., 41, 10111026, 2002.

Masson, V., Gomes, L., Pigeon, G., Liousse, C., Pont, V., Lagouarde, J.-P., Voogt, J., Salmond, J., Oke, T.R., Hidalgo, J., Legain, D., Garrouste, O., Lac, C., Connan, O., Briottet, X., Lachérade, S., and Tulet, P.: The Canopy and Aerosol Particles 
Interactions in Toulouse Urban Layer (CAPITOUL) experiment, Meteorol. Atmos. Phys., 102, 135-157, 2008.

Offerle, B., Grimmond, C. S. B., and Fortuniak, K.: Heat storage and anthropogenic heat flux in relation to the energy balance of a central European city centre, Int. J. Climatol., 25, 1405-1419, 2005.

Oke, T. R.: The urban energy balance, Prog. Phys. Geogr., 12, 471508, 1988.

Pigeon, G., Legain, D., Durand, P., and Masson, V.: Anthropogenic heat release in an old European agglomeration (Toulouse, France), Int. J. Climatol., 27, 1969-1981, 2007.

Pigeon, G., Moscicki, A. M., Voogt, J. A., and Masson, V.: Simulation of fall and winter surface energy balance over a dense urban area using the TEB scheme, Meteorol. Atmos. Phys., 102, 159-171, 2008.

Salamanca, F. and Martilli, A.: A new building energy model coupled with an urban canopy parameterization for urban climate simulations, Part II. Validation with one dimension off-line simulations, Theor. Appl. Climatol., 99, 345-356, 2010.
Salamanca, F., Krpo, A., Martilli, A., and Clappier, A.: A new Building Energy Model coupled with an Urban Canopy Parameterization for urban climate simulations, Part I. Formulation, verification and a sensitive analysis of the model, Theor. Appl. Climatol., 99, 331-344, 2010.

Synnefa, A., Stathopoulou, M., Sakka, A., Katsiabani, K., Santamouris, M., Adaktylou, N., Cartalis, C., and Chrysoulakis, N.: Integrating sustainability aspects in urban planning: the case of Athens, 3rd International Conference on Passive and Low Energy Cooling for the Built Environment (PALENC 2010) \& 5th European Conference on Energy Performance \& Indoor Climate in Buildings (EPIC 2010) \& 1st Cool Roofs Conference, Rhodes Island, Greece, 29 September-1 October 2010.

Truong, P. H.: Recommendations for the analysis and design of naturally ventilated buildings in urban areas, M. S., Massachusetts Institute of Technology, Cambridge MA, USA, 2012. 